\title{
Memory loss, behavioral changes, and slurred speech in a 49-year-old man
}

\author{
Chandril Chugh ${ }^{1}$, John M. Lee ${ }^{2}$ and José Biller ${ }^{*}$ \\ 1 Department of Neurology, Stritch School of Medicine, Loyola University Chicago, Maywood, IL, USA \\ 2 Section of Neuropathology, Department of Pathology, Stritch School of Medicine, Loyola University Chicago, Maywood, IL, USA
}

Edited by:

Osvaldo Fustinoni, Universidad de

Buenos Aires, Argentina

Reviewed by:

Osvaldo Fustinoni, Universidad de

Buenos Aires, Argentina

Maria Zurru, Hospital Italiano,

Argentina

\section{*Correspondence:}

José Biller, Department of Neurology,

Stritch School of Medicine, Loyola

University Chicago, 2160 South 1st

Avenue, Building 105, Room 2700,

Maywood, IL 60153, USA.

e-mail: jbiller@lumc.edu
A 49-year-old man presented with slurred speech, memory loss, and behavioral changes. His clinical course was marked by decline in functional status and cognition. He had poorly controlled hypertension and hyperlipidemia. Neuroimaging was remarkable for multiple subcortical white matter lesions. We discuss the diagnostic and therapeutic approach of rapidly progressing cognitive decline in the given clinical setting.

Keywords: memory loss, arterial hypertension, magnetic resonance imaging, vascular dementia
History: A 49-year-old left handed man presented to us with concerns of memory loss, slurred speech and behavioral changes. His symptoms started a year earlier while on vacation (biking) in Tuscany, Italy with his sister. His sister recalled he appeared more quiet than usual. During the ensuing days, other family members also noticed he was unusually quiet and his speech was slurred; this was attributed to fatigue from travel and wine. After he returned from vacation to his work in the Midwest, his co-workers noted similar changes. Subsequently, the patient began to suspect problems himself, when he missed a few days of work, 3 months after his symptoms were recognized while in Italy. Over the ensuing 2 months, he had increasing difficulties arriving to work on time, became more disorganized at home and at work, and had more difficulties remembering things. Six months after onset of symptoms, he was asked to see a physician by his supervisor at work. At the physician's office, the nurse thought his speech was slurred and recorded a blood pressure of 240/160 $\mathrm{mm} \mathrm{Hg}$. He was then admitted to a local hospital where he was noted to have short term memory impairment, slurred speech, word finding difficulties and behavioral changes including wandering, impulsivity and inappropriate sexual overtures to hospital staff. He was then transferred to a tertiary care hospital for further management. A detailed workup was done at the hospital, which is discussed further below. Subsequently, he had rehabilitation therapy and slow improvements were noted on his memory and organizational skills. At this time, he was able to prepare simple meals using the microwave but not the stove. He would accompany family members on errands, medical appointments, taking walks and reading. Moreover, he was independent for personal activities of daily living.

He was subsequently transferred to a rehabilitation center where he continued to show improvement in memory. Some improvement was also noticed in performing activities involving organizational and executive skills.
However, this was followed by episodes of gait difficulties and increased drowsiness, followed by an overall decline in his ability to perform tasks of daily living. He continued to have a fluctuating course and his cognition suffered a significant decline. He was witnessed to have a seizure and was subsequently started on levetiracetam.

Medications include aspirin $81 \mathrm{mg}$ daily, lisinopril-HCTZ 10-12.5 mg daily, nifedipine $90 \mathrm{mg}$ twice daily, folic acid, Coenzyme Q10, Fish oil, Vitamin B complex, atorvastatin $20 \mathrm{mg}$.

Past medical history was noteworthy for meningitis at the age of 19 , mononucleosis at the age of 29 , and recently diagnosed arterial hypertension. He worked as a manager in an Information and Technology firm. He smoked a pack of cigarettes a day for the past 20 years. He was divorced. He was not sexually active. He had family history of arterial hypertension.

Neurological examination was remarkable for a flat affect. He was disoriented to time and had deficits in attention and concentration. Four word span was $4 / 4$ at 1 min without distraction, 3/4 at $1 \mathrm{~min}$ with distraction, and $2 / 4$ at 6 and 45 min respectively. He could recite the months of the year forward in $9 \mathrm{~s}$ (paused between September and October) but took $>40 \mathrm{~s}$ backward and got stuck at June. Digit span test was 7 forward, and 3 backward. He could draw the face of a clock with correctly placed numbers but could not place the hands of a clock at the right place. He was able to read and write numbers correctly. He could add single and multi-digits correctly but made mistakes in single and multi-digit multiplication. Benton face recognition screening was normal. He had no neglect on letter cancelation test.

His speech was dysarthric with mild word finding pauses. Naming, repetition, comprehension and reading were intact. Writing was "messy" but he was able to spell correctly and the syntax was intact. Cranial nerve examination was normal except for funduscopic examination that showed focal areas of infarct lateral to the left disc 
and medial to the right disc. He had mildly spasticity in both upper extremities, and moderate spasticity in the lower extremities. He had 5/5 strength in both upper extremities. Hip flexion, knee extension, knee flexion, foot plantar flexion, foot dorsiflexion were 4/5 bilaterally. He had no tremors. He had a right "cortical fist" attitude, and bilateral palmar grasp responses. A snout reflex was present. Vibration and temperature sensation was intact except for slight reduction on the left foot. Position sense was intact. Sensation to light-touch was intact. There was no extinction to double simultaneous stimulation. Graphesthesia and stereognosis were unremarkable. He had slow and clumsy bilateral rapid alternating movements. Mild dysmetria was observed on finger to nose test bilaterally and on heel knee shin test on the left. Muscle stretch reflexes were hyperactive throughout. There was a Hoffman's sign on the right. The left plantar response was flexor. He had a right Babinski sign. There was mild ideomotor and limb-kinetic apraxia. Oral praxis was intact. He had a mildly unsteady gait. He had normal arm swing and turns, but was mildly unsteady with tandem gait. Romberg was negative.

Ancillary studies showed a normal complete blood count, normal basic metabolic profile, a serum cholesterol of $137 \mathrm{mg} \mathrm{d} / \mathrm{l}$, Triglycerides 91/mg/dl, HDL of $39 \mathrm{mg} / \mathrm{dl}$, LDL of $80 \mathrm{mg} / \mathrm{dl}$. HbAlc was 5.4. Urine drug screen was negative. Plasma homocysteine was elevated at $24.2 \mu \mathrm{mol} / \mathrm{l}$. Urine analysis and erythrocyte sedimentation rate were normal. RPR was non-reactive. Serum B12 and Folate levels, and TSH were all normal.

Transesophageal echocardiogram showed normal left and right ventricular size. The left ventricular ejection fraction was $60 \%$. There was no left atrial thrombus. The left atrial appendage was free of thrombus. There was no evidence of interatrial communication or $\mathrm{R}-\mathrm{L}$ shunt by bubble contrast study. The heart valves were normal.

MRI of the brain showed bilateral periventricular white matter and subcortical white matter ischemic changes (Figures 1 and 2). Gradient Echo imaging showed multiple subcortical

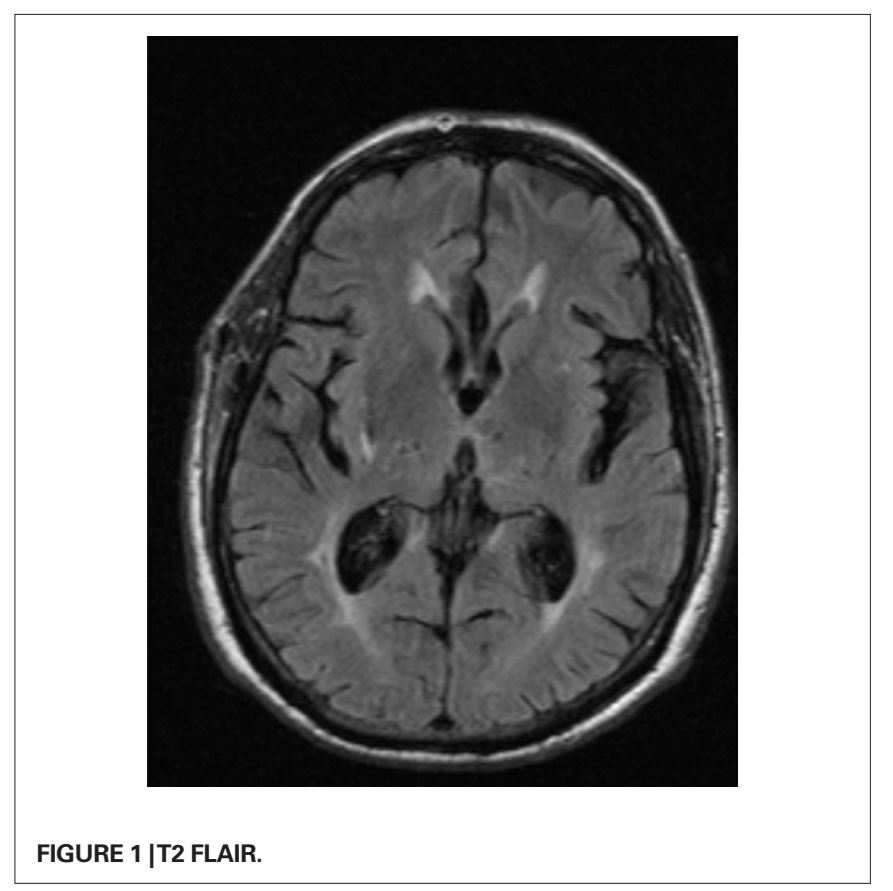

microbleeds (Figure 3). MRA (not shown) of the extracranial and intracranial circulation showed a $1.2 \mathrm{~mm} \times 2 \mathrm{~mm}$ right A1-A2 junction aneurysm, and a $1.1 \mathrm{~cm} \times 0.4 \mathrm{~cm}$ irregular outpouching from the right vertebral (V2)segment consistent with a pseudoaneurysm likely related to a chronic dissection. There was no evidence of flow-limiting stenosis within intracranial or extracranial vessels. Catheter cerebral angiogram showed a single M3 branch vessel of the right MCA with mild irregularity on magnification lateral views, a 3-mm anterior communicating artery (ACom) aneurysm, and a right V2 segment mild vertebral artery pseudoaneurysm consistent with remote dissection. There was also mild to moderate intracranial dolichoectasia, particularly of the basilar artery.

EEG revealed mild background slowing but no epileptiform activity was noticed. Chest X-ray was normal. CT chest abdomen pelvis were unremarkable. MRI of the cervical and thoracic spine were normal. Cerebrospinal fluid (CSF) testing showed, clear and colorless CSF with glucose of 59 (normal when compared to blood glucose), WBC:1, RBC:0. Cytology was negative for malignancy. Viral (HSV, VZV, CMV, JC virus), bacterial, and fungal cultures were all negative. Hypercoagulable profile, Apo E genotyping, CADASIL gene testing, autoantibody screen (C-ANCA, P-ANCA, SS-A, SS-B, complement levels, Scl-70, Anti Jo, RNP, ANA, Anti Smith Ab, cryoglobulins), and catecholamine levels. All of the above tests were normal.

The patient underwent a brain biopsy (Figures 4-7).

\section{WHAT IS YOUR DIAGNOSIS?}

Figures 4 and 5 shows thickened hyalinized barrel-shaped arterioles. Figure 6 shows a focal area of lack of myelination. The myelin loss was variable with white matter reactive astrocytosis (GFAP stain; Figure 7) and microgliosis (CD68 stain; not shown). In general, the blood vessels showed narrowing and hyalinization without occlusion. These features were consistent with subcortical arteriosclerotic leukoencephalopathy (Binswanger's disease).

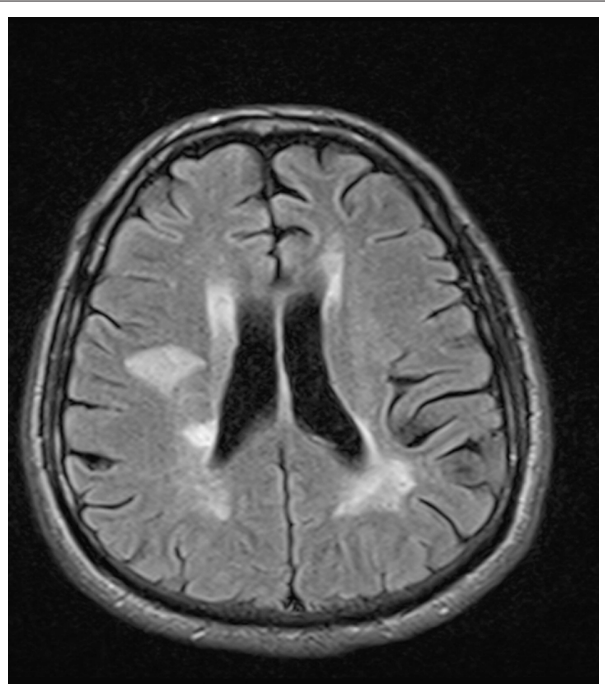

FIGURE 2 |T1 FLAIR. 


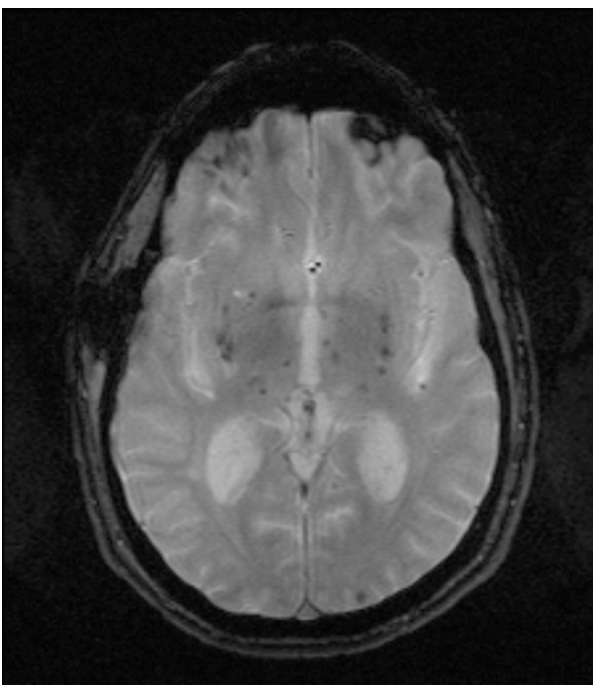

FIGURE 3 | Gradient echo.

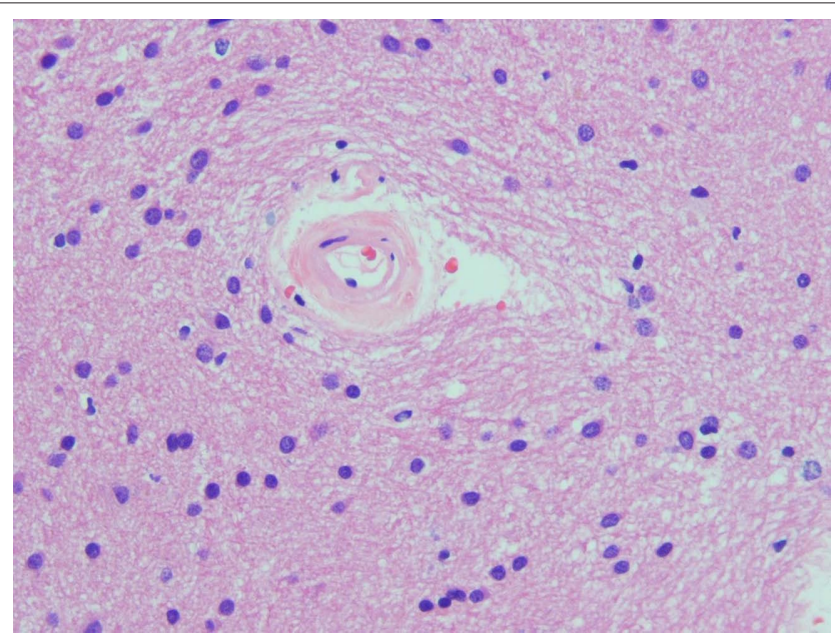

FIGURE 4 | Hematoxylin and eosin staining.

\section{CONCISE DISCUSSION}

Binswanger's disease, also known as Subcortical Arteriosclerotic Encephalopathy was initially recognized by Otto Binswanger in 1894, and Alois Alzheimer first coined the term "Binswanger's disease" in 1902 (1994; Pantoni et al., 1996). Binswanger recognized a total of eight cases in his original study, but defined the gross pathology in only one of them. Later on Alzheimer described the pathology and clinical characteristics of the disease and proposed it as a separate entity. An earlier review by Babikian and Ropper (1987) reported only 47 cases before 1987. Since then, additional cases of Binswanger's disease have been reported primarily due to the use of modern neuroimaging.

Vascular dementia is the second most common form of dementia in the United States, and causes an estimated 50\% of dementia cases in Japan. Binswanger's disease is a cause of vascular dementia (World Health Organization, 1993), and is most commonly observed in the fifth and sixth decades of life. Slightly more common among men,

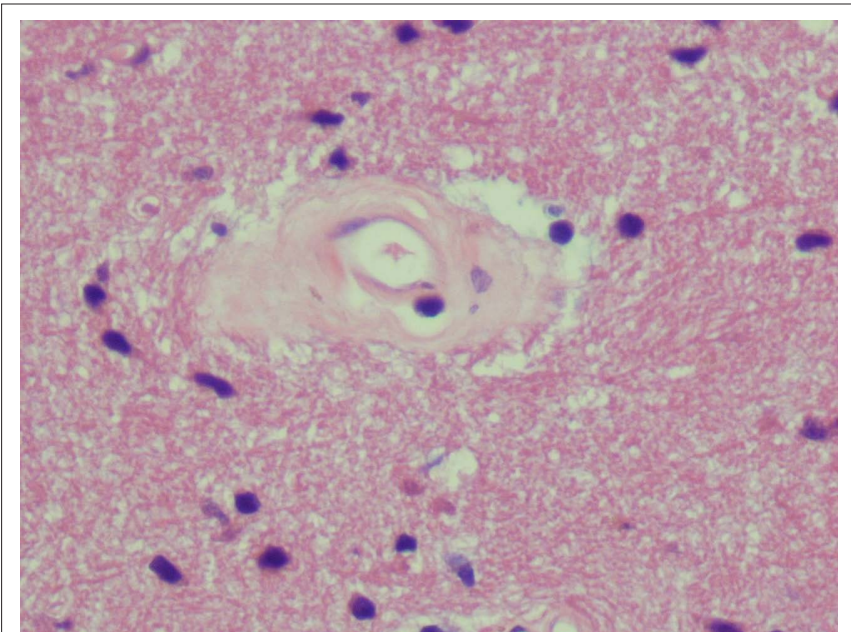

FIGURE 5 | Hematoxylin and eosin staining.

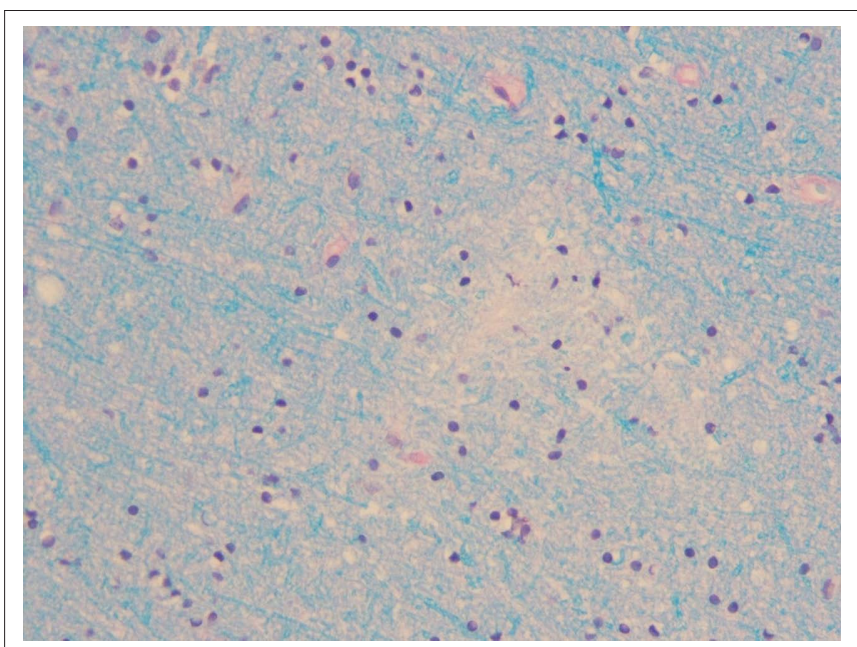

FIGURE 6 | Luxol fast blue staining.

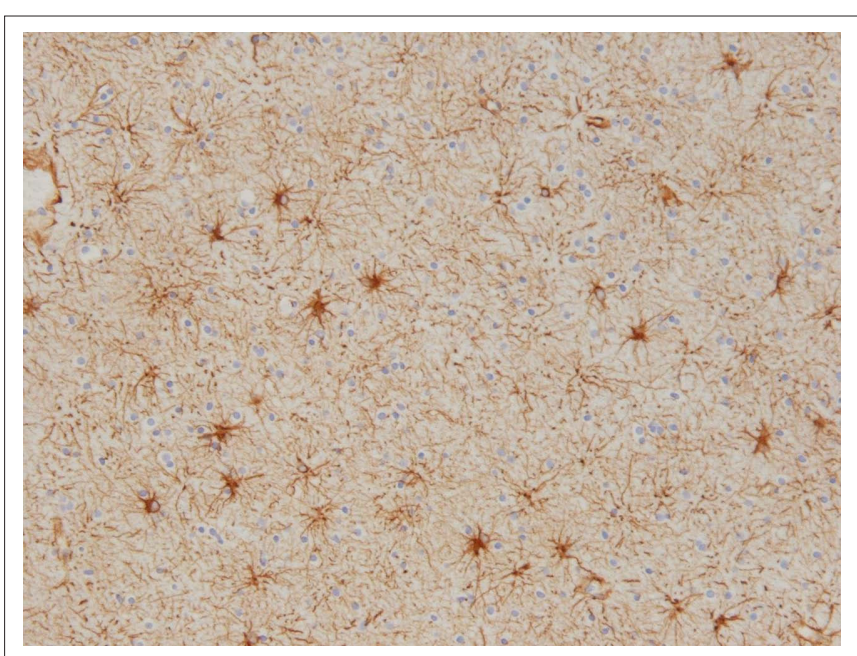

FIGURE 7 | GFAP stain. 
it is associated with arterial hypertension and diabetes mellitus. The disease starts with mild decrease in cognitive function, referred to as vascular cognitive impairment (Bowler and Hachinski, 1995, 2003). The cognitive decline is gradual in the beginning and worsens with new clinical events. As the disease progresses further decrease in the cognitive function may not be associated with new clinical events (Pohjasvaara et al., 2003). According to criteria defined by Bennett et al., Binswanger's disease is diagnosed by the presence of dementia on clinical examination or neuropsychological testing and the presence of either vascular risk factors with cerebrovascular disease or subcortical dysfunction. There should be bilateral subcortical white matter involvement, without cortical involvement on cranial computed tomography or magnetic resonance imaging (Bennett et al., 1990). The dementia is characterized by a predominantly frontal dysexecutive syndrome with mild memory impairment. Dysarthria, gait impairment, and bladder incontinence may occur early in the disease process (Baezner et al., 2008). Some patients may have mania (Caplan and Schoene, 1978), depression (Pohjasvaara et al., 2003) or mood instability with clinical fluctuations (Delong et al., 1974).

Gross pathology is characterized by gyral atrophy and lacunar infarctions involving the basal ganglia, centrum semiovale or internal capsule. The corpus callosum may be atrophic (Babikian and Ropper, 1987). Microscopically, swelling of the myelin sheath and oligodendrocytes is one of the earliest changes seen. There are microcystic areas of infarction, with relative demyelination (Pellissier and Poncet, 1989). The arterioles supplying the deep white matter exhibit lipohyalinosis with perivascular lymphocytes, thickened walls and basal lamina. There is increased deposition of normal collagen, disruption of the media, narrowed lumina and splitting of the internal elastic lamina, with some occluded vessels. The endothelium is often intact. Some vessels show hypertrophy of smooth muscle cells (Akiguchi et al., 1997).

\section{REFERENCES}

Akiguchi, I., Tomimoto, H., Suenaga, T., Wakita, H., and Budka, H. (1997). Alterations in glia and axons in the brains of Binswanger's disease patients. Stroke 28, 1423-1429.

Babikian, V., and Ropper, A. H. (1987). Binswanger's disease: a review. Stroke $18,2-12$.

Baezner, H., Blahak, C., Poggesi, A., Pantoni, L., Inzitari, D., Chabriat, H., Erkinjuntti, T., Fazekas, F., Ferro, J. M., Langhorne, P., O’Brien, J., Scheltens, P., Visser, M. C., Wahlund, L. O., Waldemar, G., Wallin, A., Hennerici, M. G., and LADIS Study Group. (2008). Association of gait and balance disorders with age-related white matter changes: the LADIS Study. Neurology 70, 935-942.

Bennett, D. A., Wilson, R. S., Gilley, D. W., and Fox, J. H. (1990). Clinical diagnosis of Binswanger's disease. J. Neurol. Neurosurg. Psychiatr. 53, 961-965.

Bowler, J. V., and Hachinski, V. (2003). Vascular Cognitive Impairment: Preventable Dementia. Oxford: Oxford University Press.
Bowler, J. V., and Hachinski, V. C. (1995). "Vascular cognitive impairment: a new approach to vascular dementia," in Cerebrovascular Disease, Vol. 4, ed. V. C. Hachinski (London: Baillière Tindall), 357-376.

Caplan, L. R., and Schoene, W. C. (1978). Clinical features of subcortical arteriosclerotic encephalopathy (Binswanger disease). Neurology 28, 1206-1215.

Delong, G. R., Kemper, T. L., Pogacar, S., and Lee, H. Y. (1974). Clinical neuropathological conference. Dis. Nerv. Syst. 35, 286-291.

Dufouil, C., Godin, O., Chalmers, J., Coskun, O., MacMahon, S., Tzourio-Mazoyer, N., Bousser, M. G., Anderson, C., Mazoyer, B., Tzourio, C., and PROGRESS MRI Substudy Investigators. (2009). Severe cerebral white matter hyperintensities predict severe cognitive decline in patients with cerebrovascular disease history. Stroke 40, 2219-2221.

Gottesman, R. F., Coresh, J., Catellier, D. J., Sharrett, A. R., Rose, K. M., Coker, L. H., Shibata, D. K., Knopman, D. S., Jack, C. R., and Mosley, T.H.Jr. (2010).

The degree of cognitive decline in Binswanger's disease correlates with the progression of white matter changes. The Cardiovascular Health Study showed a 28\% increase in white matter disease among patients older than 65 years, which correlated with decline in cognitive function (Longstreth et al., 2005). The leukoaraiosis and disability study (LADIS), observed that $10.5 \%$ of patients with mild white matter disease progressed to death or disability as compared to $29.5 \%$ with extensive white matter disease every year (Inzitari et al., 2007).The PROGRESS trial showed that patients with mild leukoaraiosis at the time of entry had a slower rate of progression to severe cognitive impairment as compared to patients with severe leukoaraiosis (Dufouil et al., 2009). Other factors correlating with cognitive decline are microvascular retinopathy (Lesage et al., 2009) and hypertension (Gottesman et al., 2010).

Management is primarily aimed at controlling risk factors like arterial hypertension and diabetes mellitus. It is important to always take into account the autoregulatory changes associated with chronic hypertension as these patients may be more likely to have hypotensive events at pressures otherwise considered as normal (Sulkava and Erkinjuntti, 1987). These events may be responsible for white matter changes leading to further memory impairment. Lipid lowering drugs and platelet antiaggregants (mainly aspirin) are used in the prevention of cardiovascular and cerebrovascular disease (Sterzer et al., 2001). In one study pravastatin improved vasomotor reactivity in small vessel ischemic disease, but had no effect on volume of leukoaraiosis (Zijlmans et al., 2004). L-Dopa has been used to improve gait in patients with features of vascular parkinsonism (Molnar et al., 1998). Memantine, donepezil, and rivastigmine have been used to benefit vascular dementia to a modest degree (Mobius and Stoffler, 2002; Wilkinson et al., 2003).

Blood pressure and white-matter disease progression in a biethnic cohort: atherosclerosis Risk in Communities (ARIC) study. Stroke 41, 3-8.

Inzitari, D., Simoni, M., Pracucci, G., Poggesi, A., Basile, A. M., Chabriat, H., Erkinjuntti, T., Fazekas, F., Ferro, J. M., Hennerici, M., Langhorne, P., O'Brien, J., Barkhof, F., Visser, M. C., Wahlund, L. O., Waldemar, G., Wallin, A., Pantoni, L., and LADIS Study Group. (2007). Risk of rapid global functional decline in elderly patients with severe cerebral agerelated white matter changes: the LADIS study. Arch. Intern. Med. 167, 81-88.

Lesage, S. R., Mosley, T. H., Wong, T. Y., Szklo, M., Knopman, D., Catellier, D. J., Cole, S. R., Klein, R., Coresh, J., Coker L.H., and Sharrett,A. R. (2009). Retinal microvascular abnormalities and cognitive decline: the ARIC 14-year followup study. Neurology 73, 862-868.

Longstreth, W. T. Jr., Arnold, A. M., Beauchamp, N. J. Jr., Manolio, T. A., Lefkowitz, D., Jungreis, C., Hirsch, C. H., O'Leary, D. H., and Furberg, C.
D. (2005). Incidence, manifestations, and predictors of worsening white matter on serial cranial magnetic resonance imaging in the elderly: the Cardiovascular Health Study. Stroke 36, 56-61.

Mobius, H. J., and Stoffler, A. (2002). New approaches to clinical trials in vascular dementia: memantine in small vessel disease. Cerebrovasc. Dis. 13(Suppl. 2), 61-66.

Molnar, F. J., Man-Son-Hing, M., St John, P., Brymer, C., Rockwood, K., and Hachinski, V. (1998). Subcortical vascular dementia: survey of treatment patterns and research considerations. Can. J. Neurol. Sci. 25, 320-324.

Oritz,J.S., and Knight, P.V. (1994). Review: Binswanger's disease, leuokoaraiosis and dementia. Age Ageing 23, 75-81.

Pantoni, L., Moretti, M., and Inzitari, D. (1996). The first Italian report on "Binswanger's disease." Ital. J. Neurol. Sci. 17, 367-370.

Pellissier, J. F., and Poncet, M. (1989). "Binswanger's encephalopathy," in Handbook of Clinical Neurology. Vascular Diseases, Part II, 54th Edn, 
eds P. J. Vinken, G. W. Bruyn, H. L. Klawans, and J. F. Toole (Amsterdam: Elsevier Science Publishers BV), 221-233.

Pohjasvaara, T., Mantyla, R., Ylikoski, R., Kaste, M., and Erkinjuntti, T. (2003). Clinical features of MRI-defined subcortical vascular disease. Alzheimer Dis. Assoc. Disord. 17, 236-242.

Sterzer, P., Meintzschel, F., Rosler, A., Lanfermann, H., Steinmetz, H., and Sitzer, M. (2001). Pravastatin improves cerebral vasomotor reactivity in patients with subcortical small-vessel disease. Stroke 32, 2817-2820.
Sulkava, R., and Erkinjuntti, T. (1987). Vascular dementia due to cardiac arrhythmias and systemic hypotension. Acta Neurol. Scand. 76, 123-128.

Wilkinson, D., Doody, R., Helme, R., Taubman, K., Mintzer, J., Kertesz, A., Pratt, R. D., and Donepezil 308 Study Group. (2003). Donepezil in vascular dementia: a randomized, placebo-controlled study. Neurology 61, 479-486.

World Health Organization. (1993). The ICD-10 Classification of Mental and Behavioural Disorders. Diagnostic Criteria for Research. Geneva: World Health Organization.
Zijlmans, J. C., Katzenschlager, R., Daniel, S. E., and Lees, A. J. (2004). The L-dopa response in vascular parkinsonism. J. Neurol. Neurosurg. Psychiatr. 75, 545-547.

Conflict of Interest Statement: The authors declare that the research was conducted in the absence of any commercial or financial relationships that could be construed as a potential conflict of interest.

Received: 12 March 2011; Paper pending publishing: 26 March 2011; accepted: 07 April 2011; published online: 28 April 2011.
Citation: Chugh C, Lee JM and Biller J (2011) Memory loss, behavioral changes, and slurred speech in a 49-year-old man. Front. Neur. 2:27. doi: 10.3389/ fneur.2011.00027

This article was submitted to Frontiers in Neurology Education, a specialty of Frontiers in Neurology.

Copyright (ㄷ 2011 Chugh, Lee and Biller. This is an open-access article subject to a non-exclusive license between the authors and Frontiers Media SA, which permits use, distribution and reproduction in other forums, provided the original authors and source are credited and other Frontiers conditions are complied with. 